\title{
STUDY OF (D- STATCOM) IMPACT IN A GRID CONNECTED (SCWEG) UNDER SYMMETRICAL FAULT
}

\author{
Ghada Mahmoud Ibrahim, Mohammed Kamal Ahmed \\ and Mohammed Ibrahim EL-Sayed \\ Department of Electrical Power Engineering, Al-Azhar University,Nasr City, Cairo, Egypt \\ ghkewan32@gmail.com, mkalshaear@yahoo.com, d_eng2009@yahoo.com
}

\begin{abstract}
This paper provides an optimized (Distributed STATCOM) control for wind electric generator. The transient behavior of squirrel cage wind electric generator (SCWEG) can be improved by injecting large amounts of reactive component during the fault recovery. This System requires a high dynamic converter, which able to work under abnormal conditions. The reactive power demand, which is necessary for fixed- speed wind turbine system (FSWTS) during faults is not met by capacitor banks installed near (SCWEG). This paper analyzes the impact of (D- STATCOM) in a grid connected (SCWEG) under fault and offers study of the whole performance of the system which can be improved by means of Distributed Static Synchronous Compensator (D-STATCOM). It is used for restoring the voltage at generator terminals under fault conditions was occurred. Simulation was carried out by MATLAB SIMULINK under abnormal conditions. Both real and reactive powers confirm that the (D-STATCOM) has good performance with (SCWEG), and the voltage profile is improved, the stability is increased and the performance of the complete system is improved.
\end{abstract}

\section{KEYWORDS :( D- STATCOM), Squirrel Cage Wind Electric Generator (SCWEG), Symmetrical Fault.}

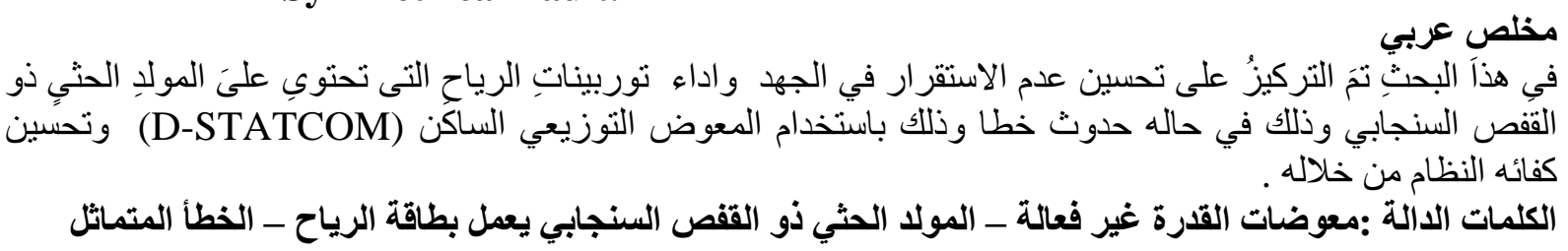
I.INTRODUCTION

With a society direction towards a future atmosphere disaster the demand for break through inventions in green energy production has increased rapidly during the last periods such as (Solar cells, hydro power, biofuels, wind...etc) and the wind turbines have all improved in performance and are sizing up.Figure.1.shows the complete system of Wind Energy Conversion System (WECS) consisting of aerodynamic components and electro- mechanical which converts wind energy to electrical energy [1].

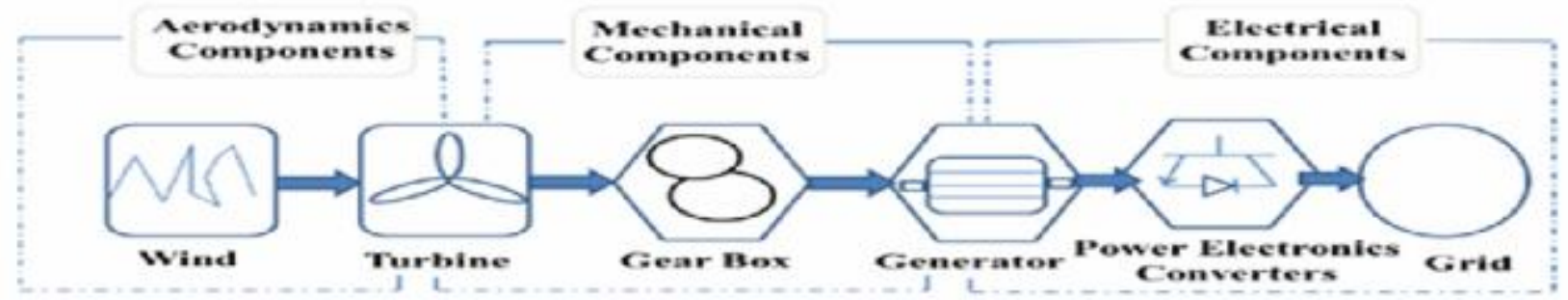

Fig .1. The components of WECS connected to grid [1] 
(SCWEG) which operates in a narrow range around synchronous speed. Fixed speed (WECS) is equipped with Squirrel Cage Induction Generator (SCIG), a multi stage gear box, soft starter and capacitor bank as shown in figure. 2. At present (FSWTS) is used widely in several (WECS) effectively and efficiently. The disadvantages of this system are high mechanical and fatigue stress on the system, no optimization of aerodynamic efficiency, requirement of enormous gear box and no voltage support to grid $[2,3]$.

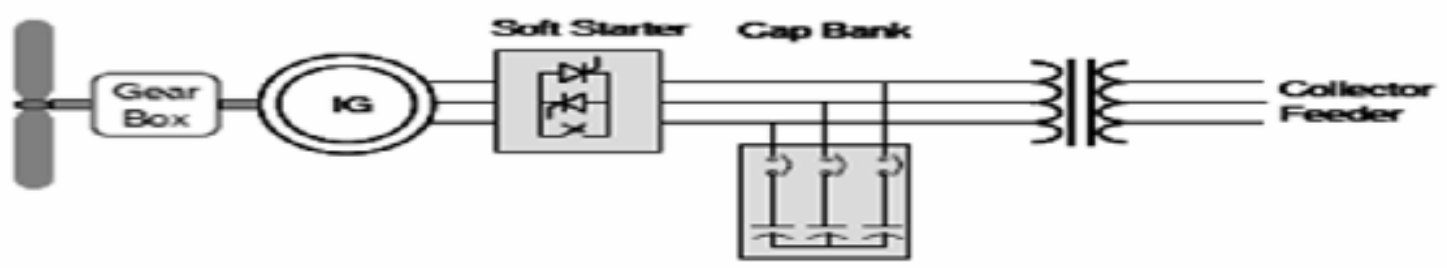

Fig. 2. Fixed speed wind turbine with (SCIG).

The configuration and operational characteristics of wind farms are the main focus of rich researches in the literature. The enhancement of (SCIG) wind farm with an (SVC) and (STATCOM) at different wind speed and varies fault conditions is discussed in [4, 5], Primary frequency control for a wind farm based on (SCIG) connected to electrical network were discussed in [6]. Similarly, other authors analyzed the operation of (D-STATCOM) during normal and abnormal grid condition with the fixed speed wind farm was simulated in MATLAB-SIMULINK, Control system for (D-STATCOM) performed during normal and abnormal grid conditions were carried out by using MATLABSIMULINK program. The performance of (FSWTS) was investigated in order to improve transient stability of (SCIG) wind farm, Stability enhancement by using a flexible Ac transmission system (FACTS) such as (D-STATCOM) or (SVC) were mentioned in [7]. All of these studies included (SCIG) based wind farms equipped with (FACTS) devices had greater stability and operational reliability -based wind farms with (FACTS) devices. This paper is concentrated on improving the performance of a grid-connected squirrel cage wind electric generator (SCWEG) by one of (FACTS) devices is a (Distributed STATCOM) under abnormal condition (symmetrical fault) by using MATLAB/SIMULINK and study the performance of the complete system with \& without (Distributed STATCOM).

This paper is arranged as follows. In section I, an introduction to the topic is given. In section II, the system description is outlined. In section III, (STATCOM) and, in section IV characteristic of (STATCOM). In section V, operation of (D- STATCOM) and control strategies presented. In section VI, studied system description with (Distributed STATCOM) under symmetrical fault is given. Finally In section VII, some conclusions are reached.

\section{II.SYSTEM DISCRIBTION}

\section{A. Wind Turbine Characteristics}

Wind is highly variable and always fluctuating, because of its time varying nature and causing stability problems.

The power extracted $\left(\mathbf{P}_{\varpi}\right)$ by a wind turbine is given by:

$$
\mathrm{P}_{\mathrm{w}}=0.5 \rho \mathrm{C}_{\mathrm{p}} \text { 通 } V_{\mathrm{w}}^{3}
$$

Where $\rho$ is the air density, ${ }^{-1}$ is the rotor swept area, $V_{\text {回 }}$ is the wind speed, and $\mathrm{Cp}$ is the power coefficient, which is a function of $\square$ and $\beta$. Again, $\beta$ is the pitch angle and $\square$ is the tip speed ratio given by:

$\lambda=\frac{\left(\mathbf{R}_{\mathbf{r}} \boldsymbol{\Omega}_{\mathbf{r}}\right)}{\mathbf{I}_{\mathrm{w}}}$

Where, $\Omega_{r}$ is the turbine shaft speed (on the low-speed side of the gear box), $\mathbf{R}_{\Xi}$ is the rotorplane radius, and the power captured by the wind turbine is heavily dependent upon tip speed ratio $\lambda$ when $B$ is unchanged. Considering the rotational speed of the wind turbine $\Omega_{\mathrm{r}}$, the mechanical torque of the wind turbine is given by [8]:

$$
\mathbf{T}_{w}=\mathbf{P}_{w} / \Omega_{r}
$$




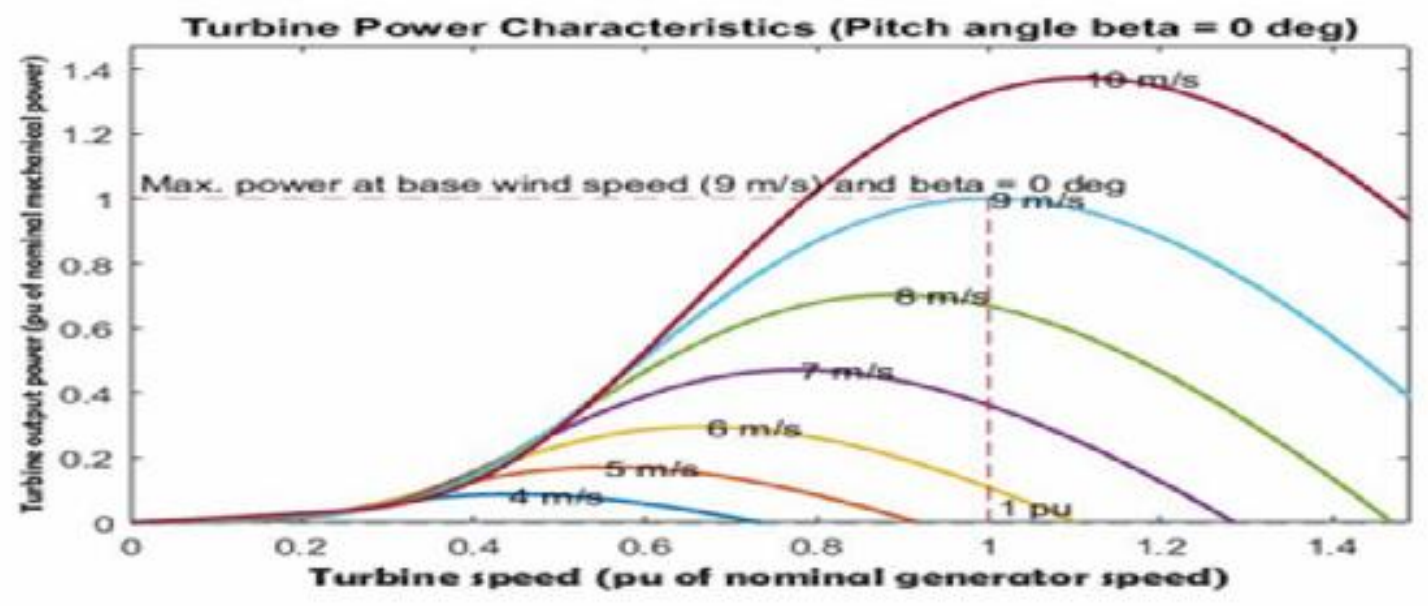

Fig.3. The output power of the turbine (pu), turbine speed (pu) at different values wind speed at $\beta=0$.

Figure.3.shows how the mechanical power extracted from the wind depends on rotor speed.

\section{B. Grid-connected Wind-driven (SCIG) System modelling}

In Figure. 4. D-Q model of an (IG) in the stationary reference frame (a) d-axis (b) q axis is illustrated. In fixed speed wind turbines-driven (SCIG), the stator is directly connected to the grid and the rotor is driven by the wind turbine. The power captured by the wind turbine is converted into electrical power by the induction generator (IG) and is delivered to the grid by the stator winding. The reactive power absorbed by the induction generator is supplied by the grid or by some auxiliary devices like capacitor banks, (SVC), (STATCOM) or synchronous condenser .The (IG) vector model is generally composed of the sets of equations such as: flux linkage equations voltage equations, and drive train model are expressed in, the following equations $[9,10]:-$.

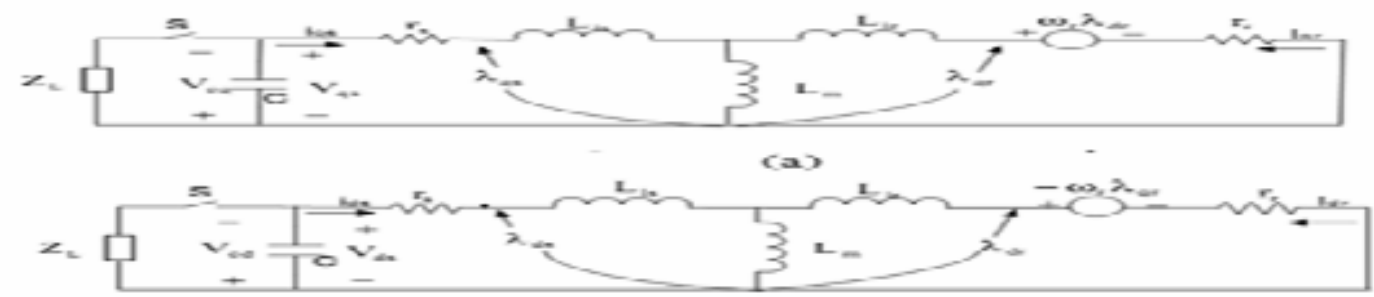

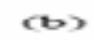

Fig. 4. D-Q model of an (IG) in the stationary reference frame (a) d-axis (b) q-axis.

- Magnetic fluxes equations

$\phi_{\mathrm{ds}}=\mathrm{Xs} \cdot \mathrm{I}_{\mathrm{ds}}+\mathrm{Xm} . \mathrm{I}_{\mathrm{dr}}$
$\phi_{\mathrm{q} s}=\mathrm{Xs} \cdot \mathrm{I}_{\mathrm{qs}} \mathrm{Xm} . \mathrm{I}_{\mathrm{qr}}$
$\phi_{\mathrm{dr}}=\mathrm{Xs} \cdot \mathrm{I}_{\mathrm{dr}}+\mathrm{Xm} \cdot \mathrm{I}_{\mathrm{ds}}$
$\phi_{\mathrm{qr}}=\mathrm{Xs} \cdot \mathrm{I}_{\mathrm{qr}}+\mathrm{Xm} \cdot \mathrm{I}_{\mathrm{qq} s}$

- Voltages equations

$$
\begin{aligned}
& V_{d s}=-R s \cdot I_{d s}+w_{s} \cdot \phi_{q s}-\frac{d}{d t} \phi_{d s} \\
& V_{q s}=-R s \cdot I_{q s}-w_{s} \cdot \phi_{d s}-\frac{d}{d t} \phi_{\mathrm{q} s} \\
& V_{d r}=-R r \cdot I_{d r}+s \cdot w_{s} \cdot \phi_{\mathrm{qr} r}-\frac{d}{d t} \phi_{d r}=0 \\
& V_{q r}=-\operatorname{Rr} \cdot I_{q r}-s \cdot w_{s} \cdot \phi_{d r}-\frac{d}{d t} \phi_{\mathrm{q} r}=0
\end{aligned}
$$

The next equations express the drive train model of SCIG wind turbines

$\mathbf{T}_{\mathrm{wt}}-\mathbf{T}_{\mathrm{mec}}=\mathbf{2} \mathbf{H}_{\mathbf{r}} \frac{d w_{r}}{d t}$ 


$$
\begin{aligned}
& \mathbf{T}_{\mathrm{wt}-} \mathbf{T}_{\mathrm{e}}=\mathbf{2} \mathbf{H}_{\mathrm{g}} \frac{d w_{\text {国 }}}{d t} \\
& \mathbf{T}_{\text {meec }}=\mathbf{T}_{\mathrm{e}}+\mathbf{2} \mathbf{H}_{\mathrm{g}} \frac{d w_{g}}{d t}+\mathbf{2} \mathbf{H}_{\mathrm{r}} \frac{d \mathbf{I}_{r}}{d t}
\end{aligned}
$$

Where $T_{W \Xi}$ the mechanical torque of rotor shaft of the wind turbine, $w_{\Xi}$ is the angular speed of turbine, $\mathbf{H}_{\Xi}$ is inertia of wind turbine rotor shaft, $\mathbf{T}_{\mathrm{mEe}}$ is the mechanical torque of generator shaft, $\mathbf{T}_{\Xi}$ is the generator electrical torque, $w_{g}$ is the angular speed of generator, $\mathrm{H}_{\Xi}$ is the inertia of generator shaft $[11,12]$.

\section{STATIC SYNCHRONOUS COMPENSATOR}

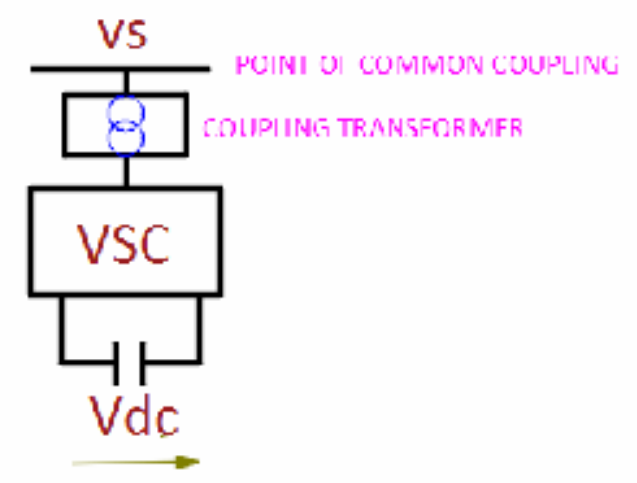

Fig .5. The schematic diagram of (STATCOM)

Static Synchronous Compensator (STATCOM) is a voltage source converter (VSC) and it is one member of the (FACTS) family devices. It is a shunt controller mainly used as a regulating device by generating/absorbing reactive power. The schematic diagram of (STATCOM) is shown in Figure. 5. (STATCOM) cannot exchange active power with the system; but it can exchange reactive power. The reactive power is fluctuated by changing the magnitude of the converter output voltage. (STATCOM) is also used to reduce voltage fluctuations in the system, supporting the stability of the grid [13].

\section{A. (V-I Characteristics of STATCOM)}

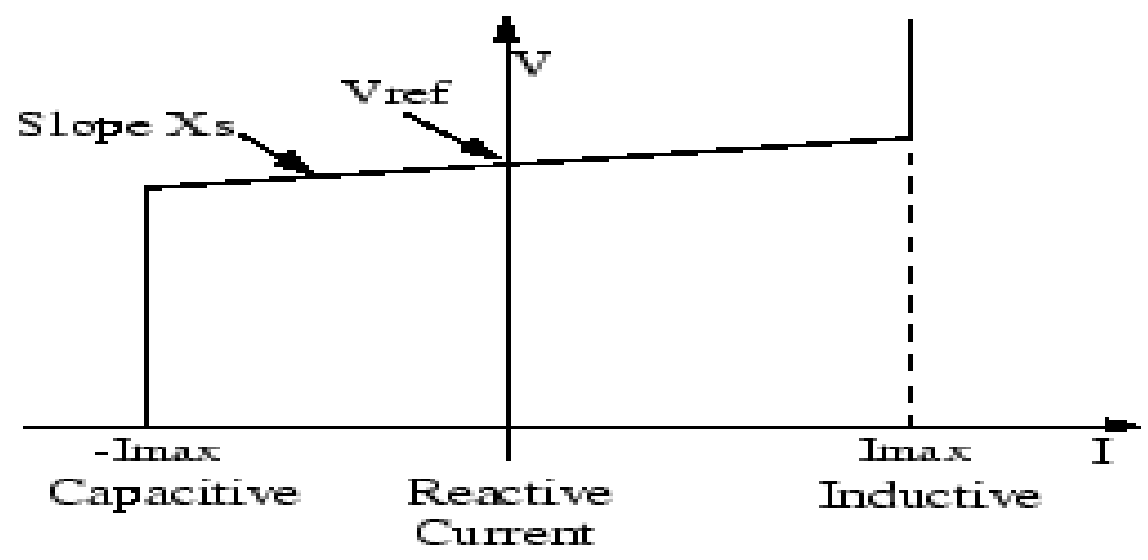

Fig.6. VI characteristic of (STATCOM).

The (STACOM) can provide both the capacitive and inductive compensation and is able to independently control it is output current the reactive current stays within the current values (Imax, Imax) imposed by the converter rating, the voltage is regulated at the reference voltage $\mathrm{V}_{\text {ref }}$, and the (V-I characteristic has the slope (drop) shown in the figure. 6).

The V-I characteristic is presented by the following equation: 


$$
\mathrm{V}=\mathrm{V}_{\text {ref }}+\mathrm{Xs} \mathrm{I}
$$

Where V: Positive Sequence Voltage (pu)

I: Reactive Current (I>0 indicates an Inductive Current)

Xs: Slope Reactance [14].

\section{V.FUNDAMENTAL CONFIGURATION AND OPERATION OF (D -STATCOM)}

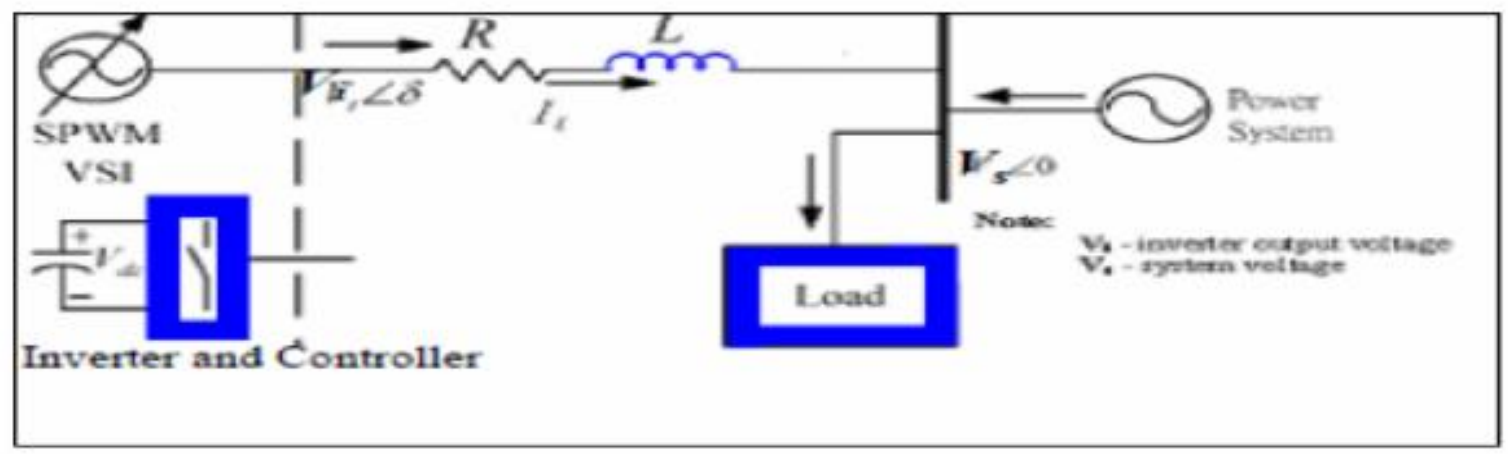

Fig. 7. Operating Principle of (D-STATCOM).

(D-STATCOM) is connected to the system where voltage quality issues are a concern as shown in figure .7. ,which are used at distribution level or at the load end .The (DSTATCOM) consist of: DC voltage source behind self-commutated inverters using (IGBT), controller and a coupling transformer (step-down transformer) that represent with resistance (R) and inductance (L). The (IGBT) inverter with a DC voltage source considered as a variable voltage source. The distribution power system can likewise be considered as a voltage source. Two voltage sources are connected by the leakage reactance of the transformer. The set of rules operation modes of (D-STATCOM) output current (I) which varies based on $\mathrm{V}_{\text {ref. }}$.

$I=\left(V-V_{r e f}\right) / X$
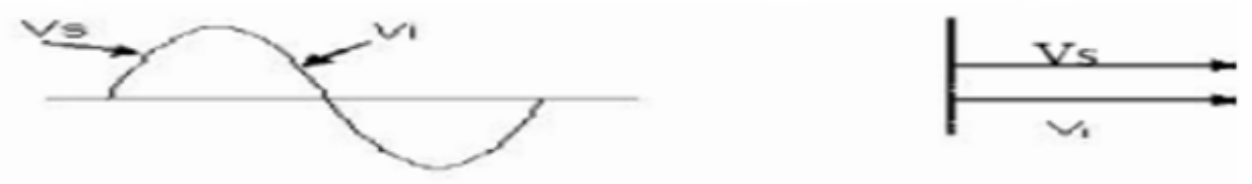

a) No-load mode $\left(V_{s}=V_{i}\right)$
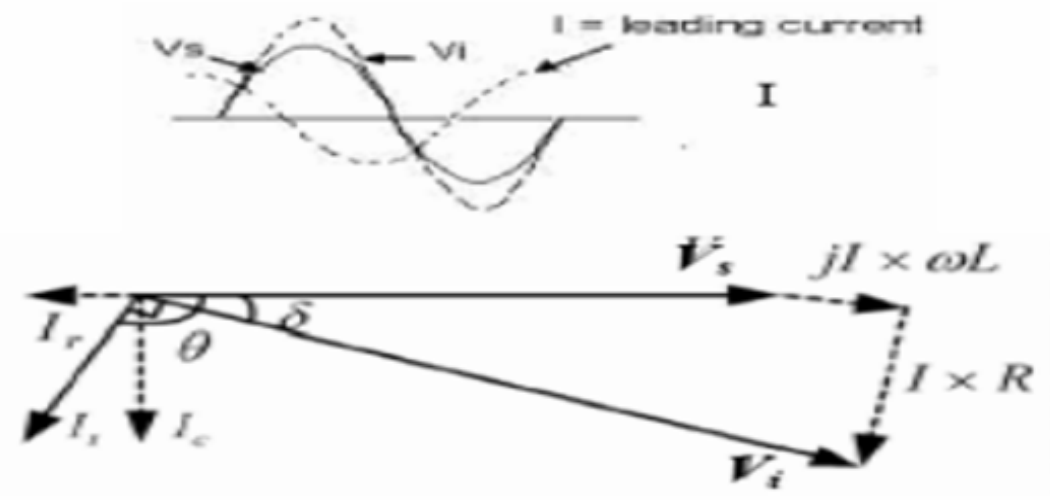

b) Capacitive mode $\left(V_{i}>V_{s}\right)$ 

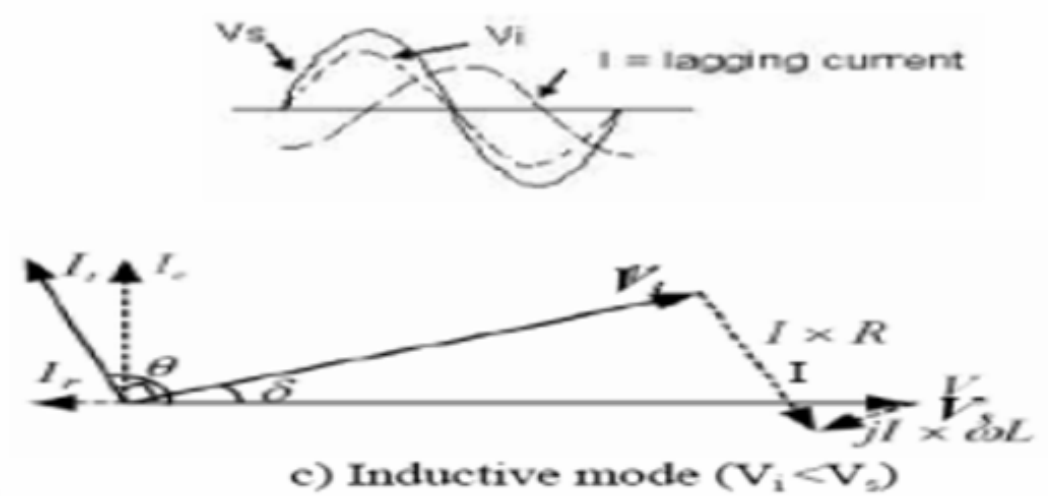

Fig. 8. Operation modes of D-STATCOM
a) No-load mode ( $\mathrm{Vs}=\mathrm{Vi}$ ) .
b) Capacitive mode ( $\mathrm{Vi}>\mathrm{Vs})$.
c) Inductive mode $(\mathrm{Vi}<\mathrm{Vs})$.

The voltage Vi of the (D-STATCOM) is the effective output voltage and $\delta$ is the power angle. The Ac Voltage control is accomplished by firing angle control. The controller of the (DSTATCOM) is utilized to operate the inverter in such a way that the phase angle between the inverter voltage and the line voltage is dynamically adjusted so that the (D-STATCOM) generates or absorbs the required reactive power (Q) in VAR at the point of connection. Figure.8. $(\mathrm{a}, \mathrm{b}, \mathrm{c})$ demonstrates the different operation modes of the (D-STATCOM) output current (I), which changes relying on $\mathrm{Vi}$. If $\mathrm{Vi}=\mathrm{Vs}$, in this case the reactive power (Q) is zero and the (D-STATCOM) does not generate or absorb reactive power (no load mode). When Vi is greater than Vs, the (D-STATCOM) demonstrates an inductive reactance connected at its terminal. The current (I) flows through the transformer reactance from the (D-STATCOM) to the Ac system, and the device generates capacitive reactive power. If $\mathrm{Vs}$ is greater than $\mathrm{Vi}$, the (D-STATCOM) demonstrates the system as a capacitive reactance. Then the current flows from the Ac system to the (D-STATCOM), resulting absorbing inductive reactive power [15].

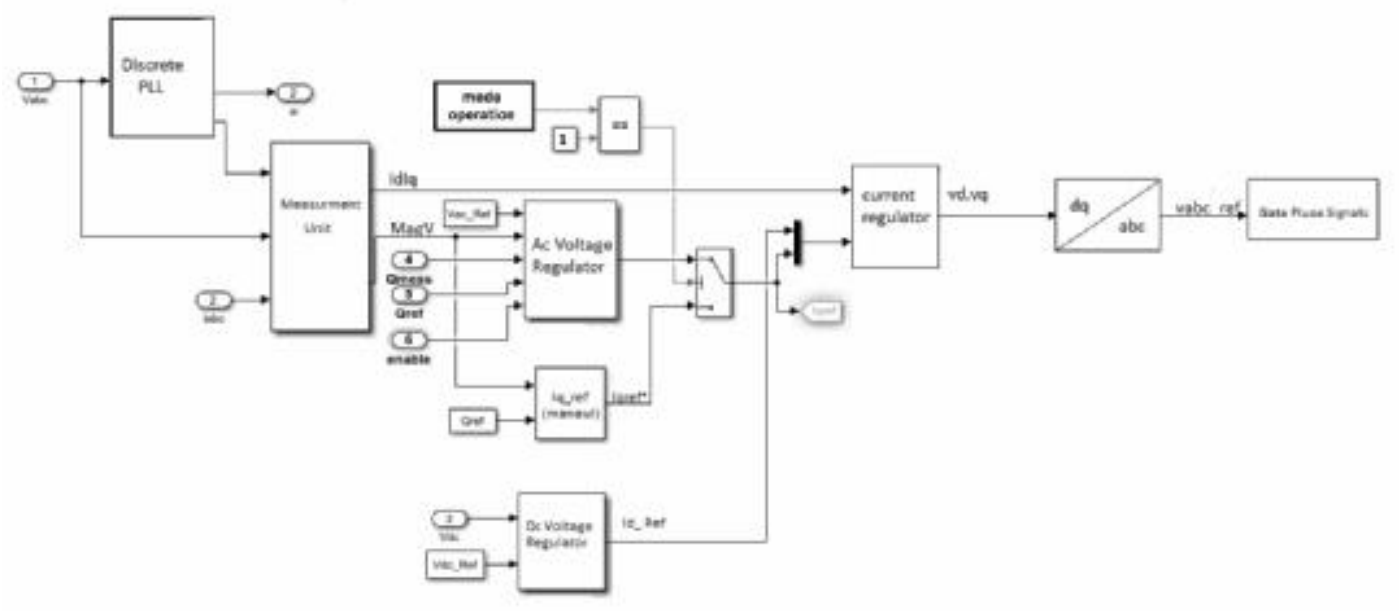

Fig. 9. The (D-STATCOM) control strategy

The (D-STATCOM) control strategy is shown in figure.9, and it is based on the dq rotating reference frame. Phase Locked Loop (PLL) is employed, to synchronize on the positive sequence component of the three-phase voltage $\mathrm{Vabc}$ and to provide the angle è $=w t$ to the 
transformation abc -to- dq and its inverse. A measurement system is also included to measure the $\mathrm{d}$ and q components of the ac positive sequence voltage and current to be controlled ( $\mathbb{I}_{\mathbb{\Xi}}$, $I_{q}, V_{d}$ and $\left.V_{q}\right)$ and the dc voltage $V_{d c}$. The Dc Voltage Regulator is responsible for keeping the constant dc voltage. This regulator provides the active current reference Id_Ref. The Ac voltage regulator is responsible for controlling the terminal voltage through the reactive power exchange with the ac network. This regulator provides the reactive current reference, Iq_ref., which allows small variations around the terminal voltage. In the current regulator, there are other two regulators, which determine references values of $V_{d}$ and $V_{q}$ which are sent to the PWM signalgenerator of the converter, after a dq -to- abc transformation. Finally, Vabc_ref are the three phase voltages desired at the converter output.

\section{STUDIED SYSTEM DESCRIPTION}

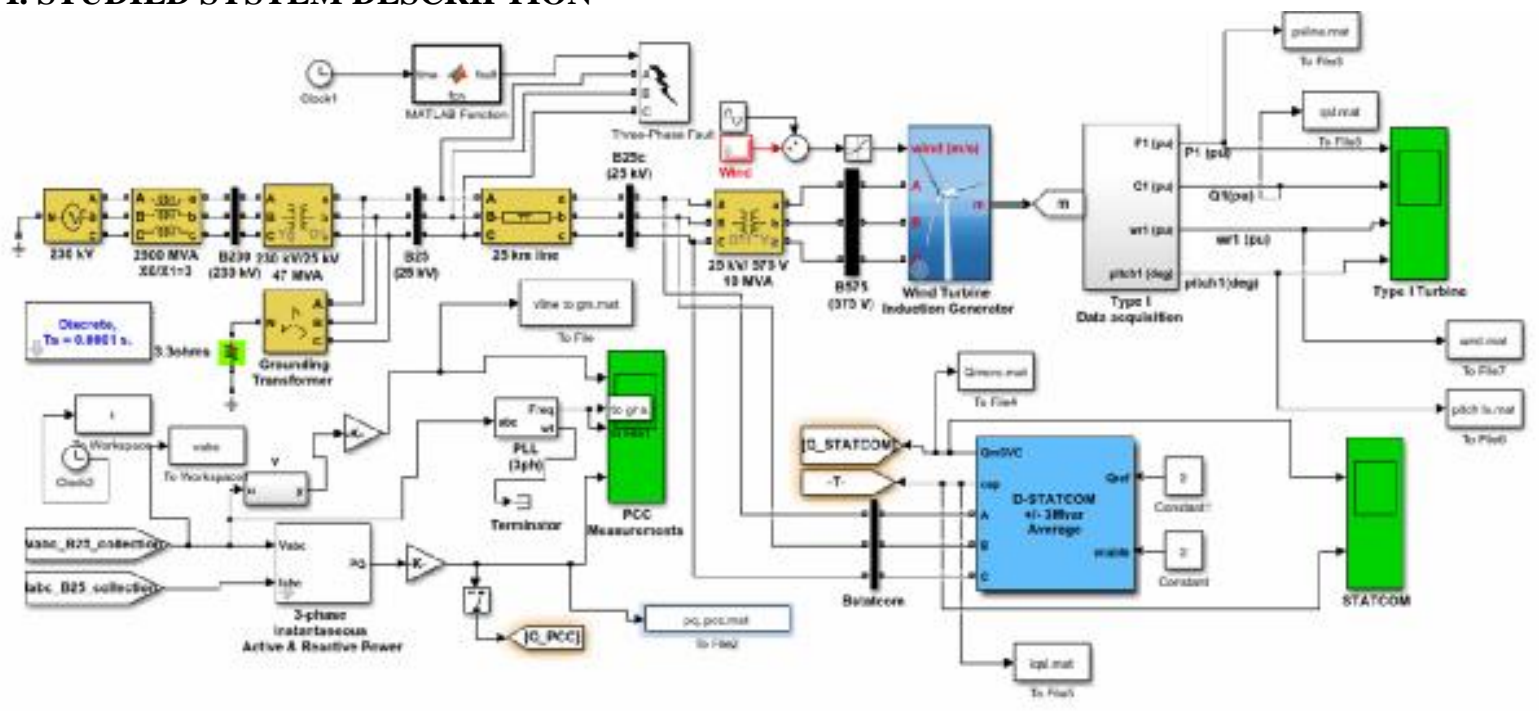

Fig. 10. (Simulink block diagram) of (SCWEG) with (D-STATCOM).

Figure .10. Shows a Simulink block diagram) of a (SCWEG) under study. A simulation model of (SCWEG) consisting of $(4 * 1.5) \mathrm{MW}$ is connected to a $230 \mathrm{kV}$ distribution system exports power to a $230 \mathrm{kV}$ grid through a $25 \mathrm{kV}$ feeder. The stator of (SCIG) is connected directly to the grid, frequency= $60 \mathrm{~Hz}$ and therefore the rotor is driven by a variable pitch wind turbine. The pitch control system is used to limit the generator output power at its nominal value for winds greater than nominal speed $(9 \mathrm{~m} / \mathrm{s})$. Capacitor banks are connected at low voltage bus of every wind turbine (400 KVAR for $1.5 \mathrm{MW}$ turbines) that provides the constant no load demand.

A 3 MVAR (D-STATCOM) is connected at bus B25 because bus B25 is the main bus, which connects the (SCWEG) with the grid, so this bus is taken as the monitoring point of the studied system. The monitoring equipments are placed at the main bus B25 for knowing the generated active power from the (FSWT) driven (IG) to the grid, the total absorbed or generated reactive power and voltage at the Main bus of the wind turbine induction generator, and generator speed. The (SCWEG) must stay connected during a fault. The fault occurs at $4 \mathrm{Sec}$ and clear at $4.5 \mathrm{Sec}$, the impact of (D-STATCOM) is studied throughout the symmetrical fault in the distribution line system at $25 \mathrm{~km}$. Simulation is performed in MATLAB SIMULINK.

\section{Case study: Three-phase symmetrical fault}

In this case, for transient analysis, a three-phase symmetrical fault (3line fault) is simulated in distribution lines at $25 \mathrm{~km}$ from the (SCWEG). 


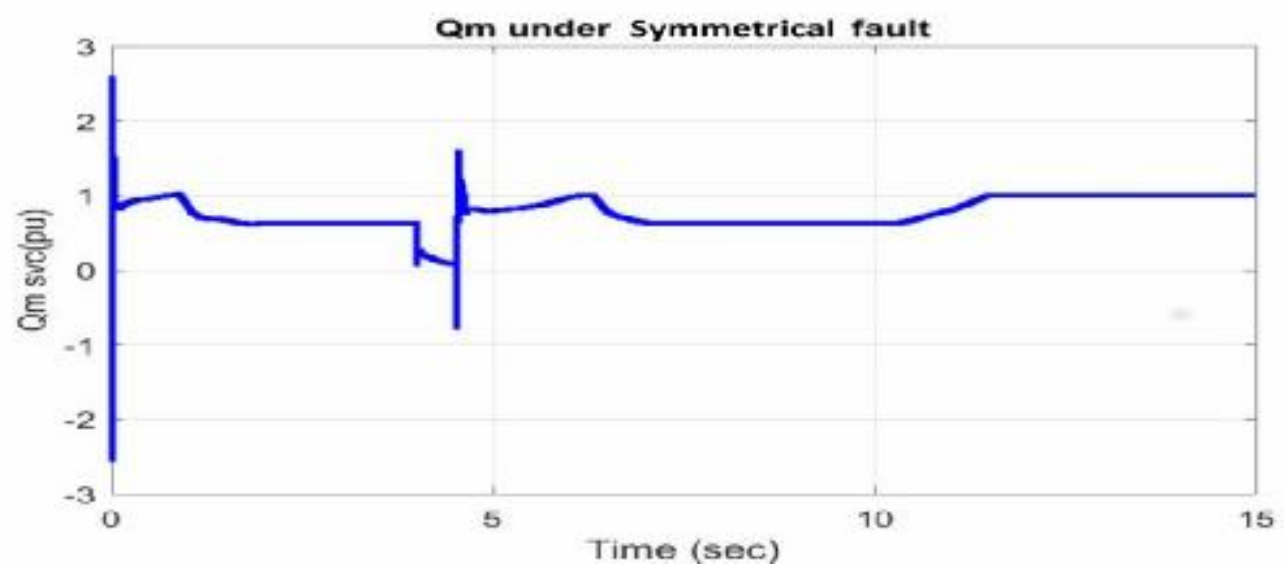

Fig.11. Reactive power contribution by the (D-STATCOM).

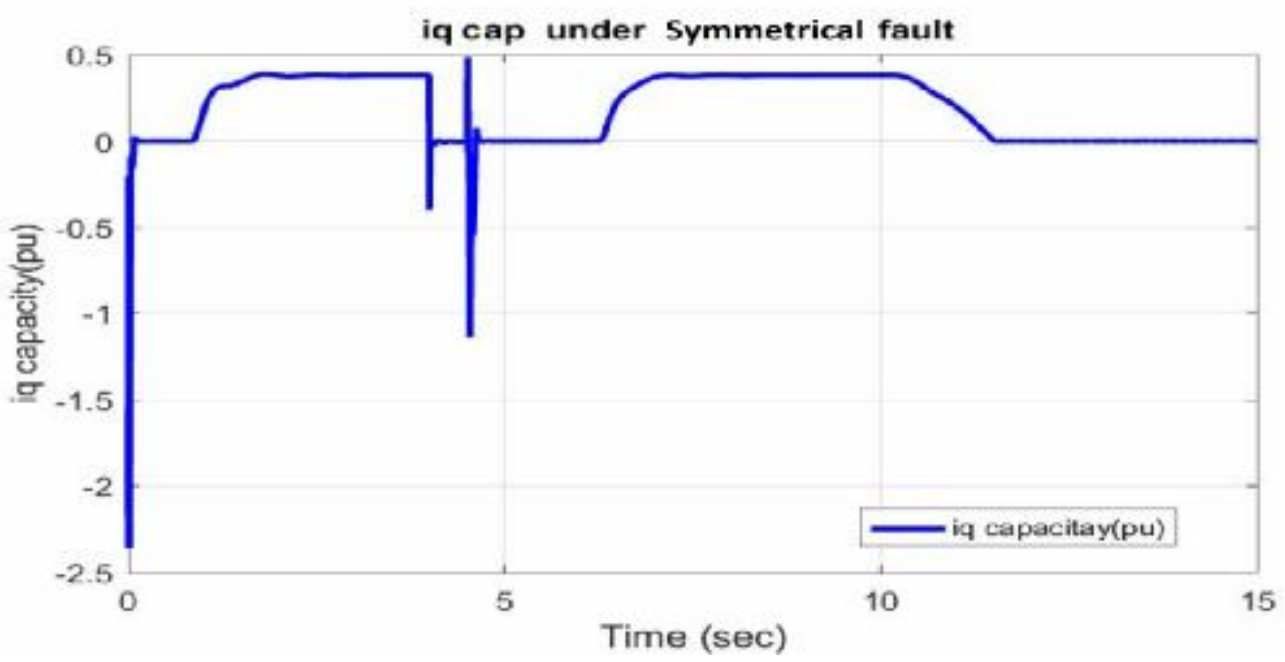

Fig. 12. Reactive current contribution by the (D-STATCOM).

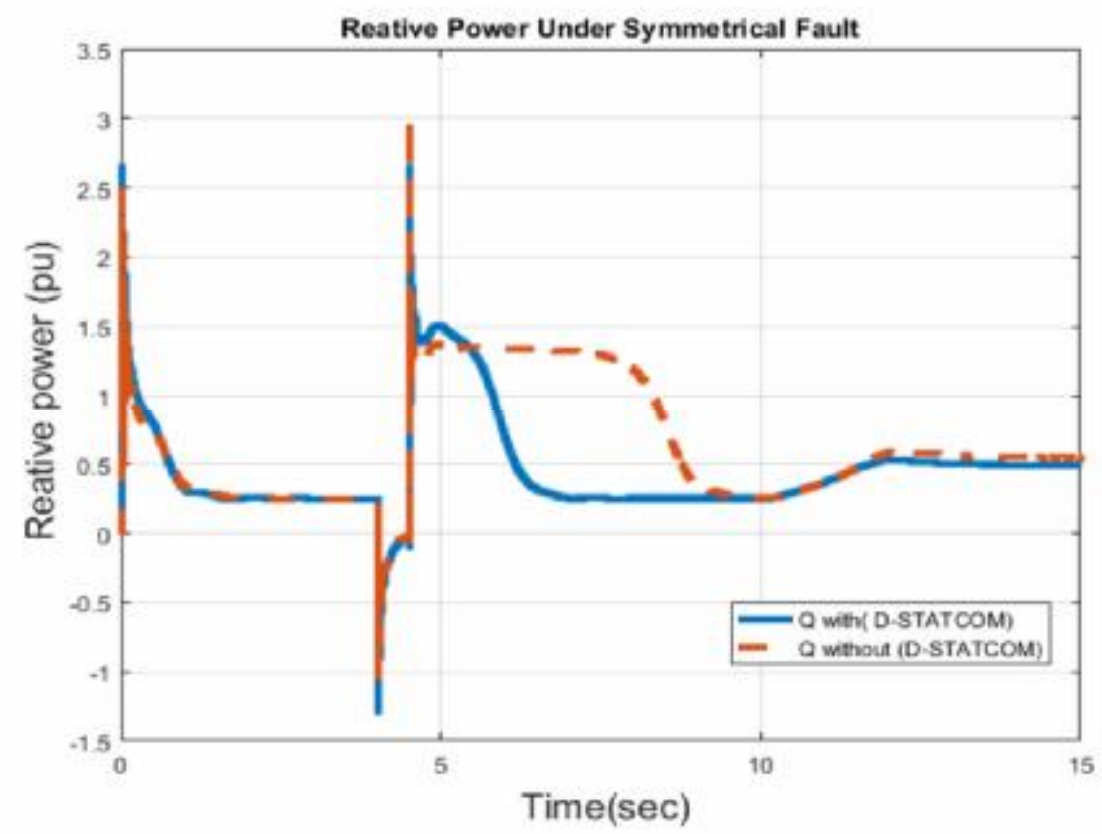

Fig. 13. Variation in reactive power supplied by the grid. 
(D-STATCOM) is switched to supply the reactive component, required by the machine during the fault and after its clearance, as shown in Figure. 11. , Figure.12. The variation in reactive power drawn from the grid with \&without (D-STATCOM) is shown in Figure. 13. It is clear that the reactive power requirement from the grid increased to very high value after the fault clearance, but it is limited in the presence of (D-STATCOM).

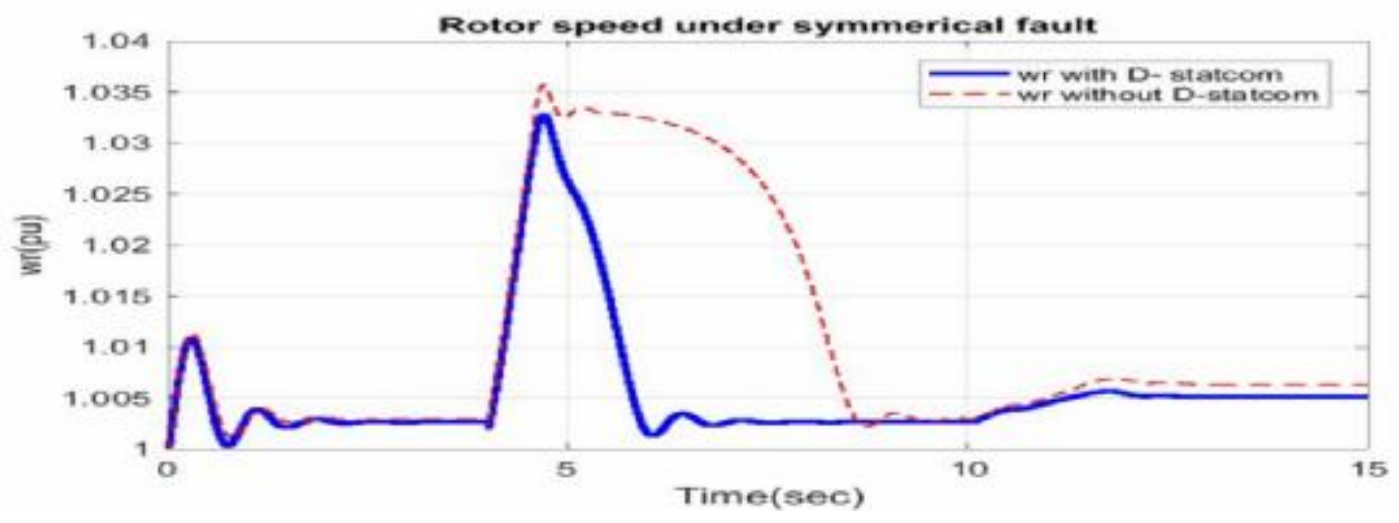

Fig. 14. Rotor speed Variation with\& without (D- STATCOM)

Rotor speed variations of this system with \&without (D-STATCOM) were analyzed during the symmetrical fault, in figure. 14. shows the increase in rotor speed as (1.036 p.u) without the (D-STATCOM) is indicated. However, it is restricted to a lower value (1.032 p.u by the compensator (D-STATCOM) when the fault is cleared it comes back to normal speed at time $6 \mathrm{sec}$ and the rotor speed stability is increased. If we compare the times of rotor speed recovery, we find that it's faster with (D-STATCOM).

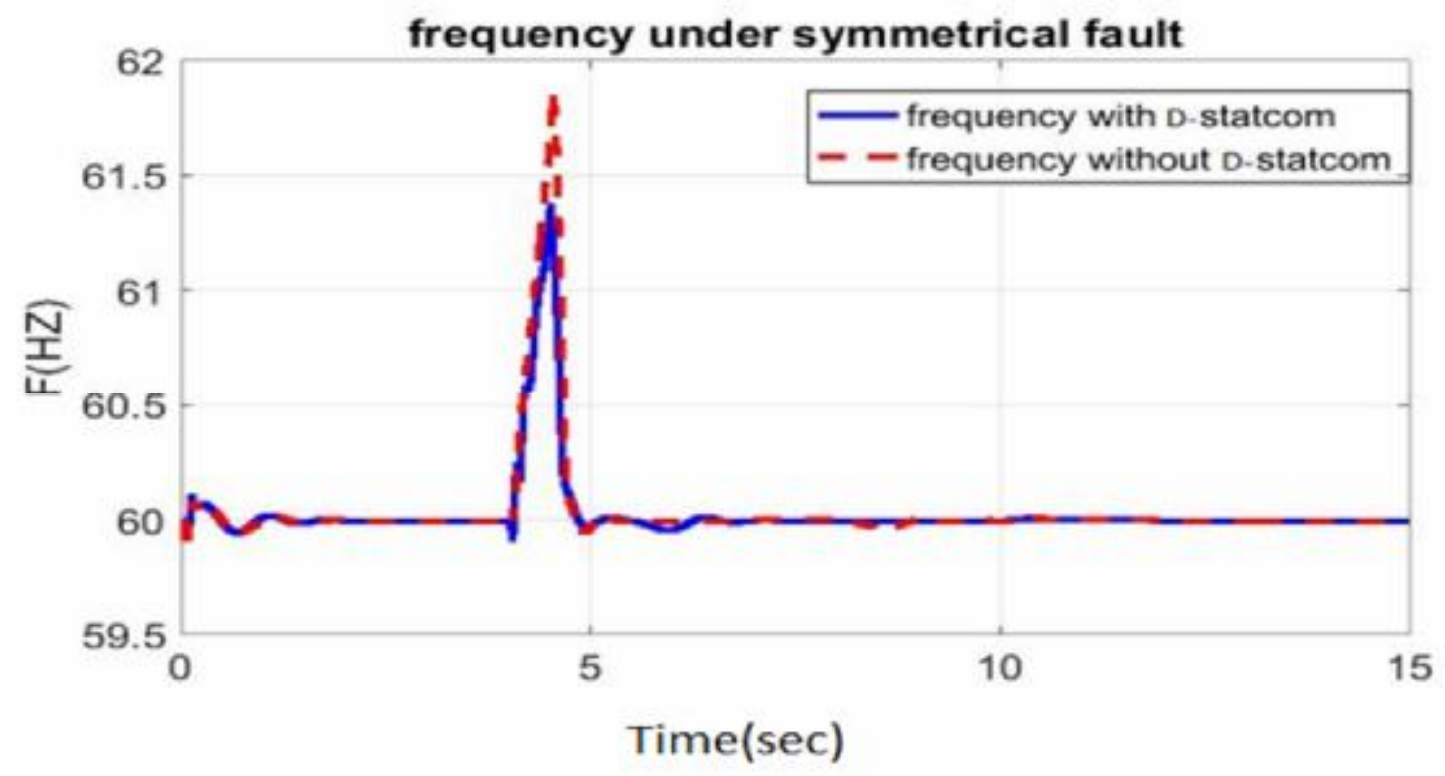

Fig. 15. Frequency behaviour with \& without (D-STATCOM).

The frequency behaviour without (D-STATCOM) reaches 61.8(HZ) during symmetrical fault and falls to $61.3(\mathrm{HZ})$ with (D-STATCOM) and the stability is reached after the fault cleared, as shown in Figure. 15. 


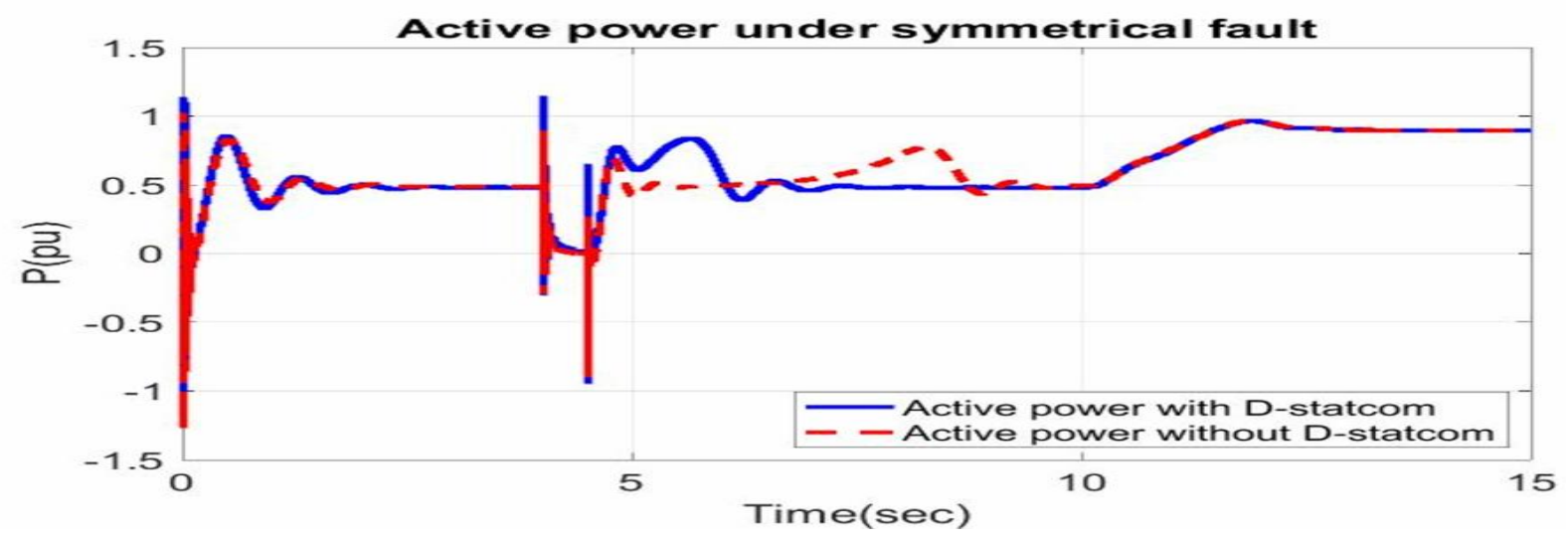

Fig.16. Active power output with \& without (D-STATCOM).

Variations of, active power generated form (SCWEG), during a three-line fault (symmetrical fault) with\& without (D-STATCOM) is shown in Figure.16. It can be seen that the active power is stabilized faster with (D-STATCOM) compared to the case without (D-STATCOM).

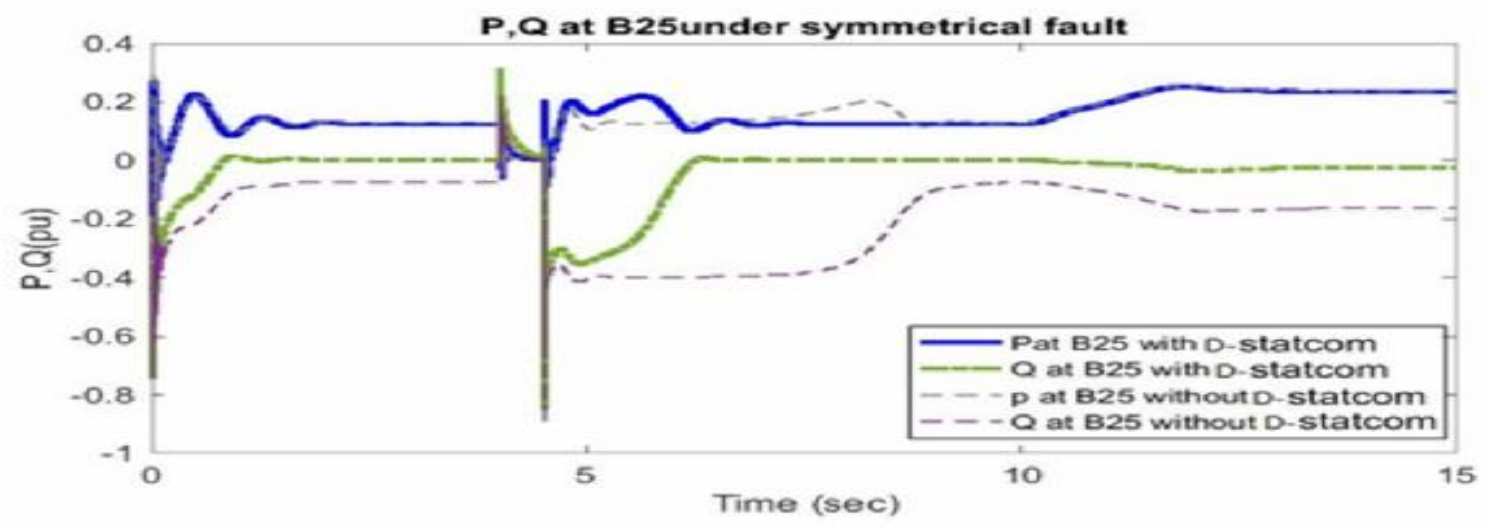

Fig. 17. Variation of $P, Q$ at $B 25$ with \& without (D-STATCOM).

Variations of, active power, and total absorbed reactive power during three-line fault (symmetrical fault with \&without (D-STATCOM)) is shown inFigure.17.According to the simulation results, the curves presented above show the importance of the (D-STATCOM) compensation at bus 25 after the fault cleared and reaches its stability.

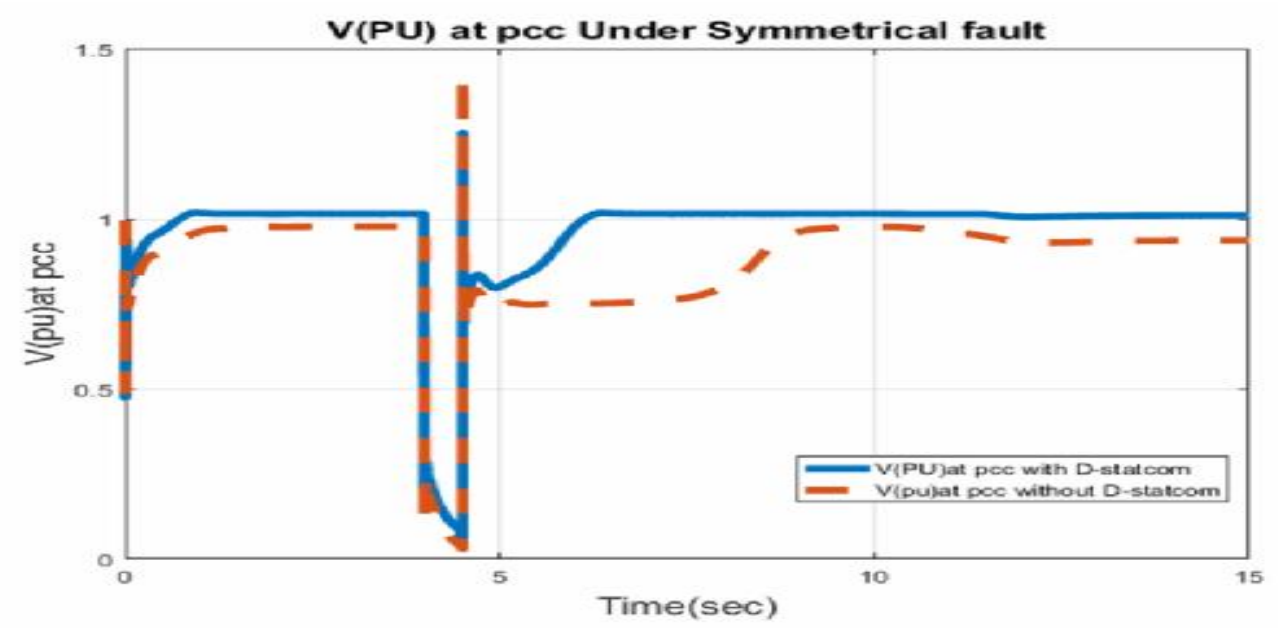

Fig. 18. Voltage at PCC with \& without (D-STATCOM). 
The voltage at Point of Common Coupling (PCC) at B 25 without (D-STATCOM) after the fault cleared didn't returned to it is normal value $1(\mathrm{pu})$ and reduced to a lower value. But with (D- STATCOM) the voltage returned to it is normal value 1(pu) after the fault is cleared and the system is recovered very fast with (D- STATCOM) as shown in Figure.18.

\section{VII .CONCLUSION}

Dynamic changes in reactive power demand can be smoothly compensated using (DSTATCOM) which means a reduction of the unforeseen burden on the grid. Throughout abnormal grid conditions such as voltage dips and faults, (D-STATCOM) will enhance the rotor speed stability of the (SCWEG) and help to avoid its disconnection from the grid. (DSTATCOM) is used to precisely regulate system voltage, improve the profile voltage of the system, reduce transient voltage disturbances, and reduce voltage harmonics.

In this paper the performance of the (D-STATCOM) with (SCWEG) is evaluated. The results obtained allow to conclude that the (D-STATCOM) provides voltage support following voltage dips that arise from external (symmetrical fault) occurrence, reducing voltage drops and increasing the stability margin of the system.

\section{REFERENCES}

1. Wei Qiao, , July 2008 "Integrated Control of Wind Farms, FACTS Devices and the Power Network Using Neural Networks and Adaptive Critic Designs", Georgia Institute of Technology, Ph.D. dissertation.

2. Datta Rajib, Ranganathan VT, , (2002) "Variable speed wind power generation using doubly fed wound rotor induction machine - a comparison with alternative schemes," IEEE transactions on Energy conversion, Vol. 17, No. 3, pp. 414-421.

3. Mittal Rajveer, Sandhu KS, Jain DK., , (2010). "An Overview of Some Important Issues Related to Wind Energy Conversion System (WECS)", International Journal of Environmental Science and Development, Vol. 1, No. 4

4. Noureldeen, Rihan M, Hasanin. Jain 2011 "Stability improvement of fixed speed induction generator wind farm using STATCOM during different fault locations and durations". Ain Shams Eng;2(1):1-10.

5. Gounder YK, Nanjundappan D, Boominathan V. 2016 "Enhancement of transient stability of distribution system with SCIG and DFIG based wind farms using STATCOM". IET Renew Power Gener;10(8):1171-80.

6. Elyaalaoui, Kamal, Mohammed Ouassaid, and Mohamed Cherkaoui. (2018) "Primary frequency control using hierarchal fuzzy logic for a wind farm based on SCIG connected to electrical network." Sustainable Energy, Grids and Networks 16: 188195. 88-195.

7. V. M. Hrishikesan, K. Venkatraman, M.P. Selvan, S.Moorthi, 2014 "Application of D-STATCOM in SCIG based Wind farms duringNormal and Abnormal Grid Conditions", National Institute of Technology Tiruchirappalli,978-1-4799-51413/14/\$31.00 (C) IEEE.

8. MagdiRagheb and Adam M. Ragheb , 2011"Wind Turbines Theory - The Betz Equation and Optimal Rotor Tip Speed Ratio" , InTech, Available at http://www.intechopen.com/books/fundamental-and-advanced-topicsinpower/wind-turbines-theory-the-betz-equation-and-optimal-rotor-tip-speed-ratio,.

9. wu, Y. Lang, N. Zargari, S. Kouro, "power conversion and control of wind energy systems," IEEE press, wiley, Canada 2010.

10. Martins, M. Perdana, A. Ledesma, P Agneholm,E. Carlson, O.(2007) ,Validation of fixed speed wind turbine dynamic models with measured data. RenewableEnergy, [Online] 32, 1301-1316 Available from: www.sciencedirect.com [Accessed March 2007].

11. Fernandez LM, García CA, Saenz JR, Jurado F. 2009 "Equivalent models of wind farms by using aggregated wind turbines and equivalent winds". Energy Convers Manage;50(3):691-704.

12. Heier S. Grid integration of wind energy conversion systems. Chicester: JohnWiley\& Sons; 1998. 
13. Pahade and N. Saxena, 2013 "Transient stability improvement by using shunt FACT device (STATCOM) with Reference Voltage Compensation (RVC) control scheme," InternationalJournal of Electrical, Electronics and Computer Engineering,vol. 2, pp.712 .

14.Amit Garg, June 2013,"Dynamic Performance Analysis of IG based Wind Farm with STATCOM and SVC in MATLAB /SIMULINK", International Journal of Computer Applications Volume 71- No.23,.

15. Reed, G. F.; Takeda, M. ;Iyoda ,I. 1999. "Improved power quality solutions using advanced solid-state switching and static compensation technologies". IEEE PowerEngineeringSociety 1999 Winter Meeting, 31Jan. - 4Feb. 1999. NewYork, NY, USA. IEEE. vol.2. pp: 1132-1137 . 